\section{Salud, beneficencia y mutualismo: la colonia española en la Ciudad de México durante el Porfiriato}

\author{
Health, beneficence and \\ mutualism: the Spanish \\ colony in Mexico City during \\ the Porfirio Díaz regime
}

GUTIÉRREZ DOMÍNGUEZ, María del Mar. Salud, beneficencia y mutualismo: la colonia española en la Ciudad de México durante el Porfiriato. História, Ciências, Saúde - Manguinhos, Rio de Janeiro, v.28, n.2, abr.-jun. 2021, p.437454.

\section{Resumen}

El artículo se acerca a las iniciativas de salud impulsadas por la colonia española en la capital mexicana durante el Porfiriato. Primero, se explica la importancia que adquirió la Sociedad de Beneficencia Española (SBE) durante este periodo. Se ubica la SBE en el contexto de expansión y profesionalización de los servicios médicos por el Estado, y la red de relaciones sociales, políticas y económicas entre los individuos prominentes de la colonia y el gobierno de Porfirio Díaz. Posteriormente, se indaga en las insatisfacciones que generó la SBE, que dio lugar a la fundación de un efímero proyecto de características mutuales, protagonizado por dependientes de comercio españoles: la Quinta de Salud.

Palabras clave: Beneficencia Española; Quinta de Salud; colonia española; dependientes de comercio; México.

\section{Abstract}

This article examines health initiatives led by the Spanish colony in the Mexican capital during the Porfirio Díaz regime. Firstly, it explains the importance acquired by the Sociedad de Beneficencia Española (SBE) during this period. It situates the $S B E$ within the context of the expansion and professionalization of medical services by the state, the network of social, political and economic relationships among prominent individuals in the colony, and the government of Porfirio Díaz. Then it examines the reasons for dissatisfaction with the SBE, which led to the founding of a short-lived project for a mutual society, led by Spanish store clerks: the Quinta de Salud.

Keywords: Beneficencia Española; Quinta de Salud; Spanish colony; store clerks; Mexico. 
$\mathrm{E}^{\mathrm{I}}$ objetivo de este artículo es realizar un acercamiento a las iniciativas, los proyectos y las instituciones de salud de la colonia española residente en la Ciudad de México que existieron durante el periodo del Porfiriato (1876-1911): la Sociedad de Beneficencia Española (en lo sucesivo, SBE) y la Quinta de Salud. La existencia y duración de ambas instituciones es profundamente disímil, pues mientras la primera se fundó en 1842 y pervive hasta la actualidad, así como es considerada la principal asociación en materia de salud dentro de la colonia española en la Ciudad de México; la segunda existió por un corto periodo de tiempo, tan solo durante unos pocos meses de 1901. Aunque la función de estas asociaciones era similar, relacionada con la gestión de las cuestiones de salud para los españoles residentes en la capital mexicana, la base constitutiva de cada una de ellas fue diferente, por lo que la intención es comprender la función que desempeñaron en la sociedad de recepción y problematizar su labor asistencial en un contexto histórico determinado, tal y como se explicará a continuación.

Las investigaciones de Alicia Gil Lázaro acerca de la Beneficencia Española en la Ciudad de México constituyen un importante referente para este estudio. Esta autora ha analizado la cobertura médico-sanitaria de la SBE, las prácticas mutualistas, el discurso caritativo y la repatriación asistida de españoles practicados por esta institución; a partir de las memorias anuales de la asociación, fundamentalmente (Gil Lázaro, 2015, 2014, 2011a, 2011b, 2010a, 2010b, 2008). Además, existen três estudios monográficos sobre la SBE - muy tempranos - realizados por descendientes de españoles, que aunque tienen un tono apologético y un escaso aparato crítico, arrojan datos de interés (Carreño, 1942; Laguarta, 1955; Matute, 1966). En el presente artículo se incorpora información relevante hallada en el Archivo Histórico de la Ciudad, referente a los espacios que ocupaba la SBE antes de contar con un asilo propio o cuestiones de financiación, documentos que no han sido considerados en estudios anteriores. También se pone el acento en las insatisfacciones que generó esta asociación y se presenta el efímero proyecto de la Quinta de Salud. Pese a su brevedad, esta iniciativa presenta interés porque proponía un tipo de asociacionismo de base mutual, muy común entre las colectividades de inmigrantes del Cono Sur americano, pero practicamente inexistente para el caso mexicano.

La SBE y la Quinta de Salud representan una ventana a las necesidades y aspiraciones de la colectividad española residente en la capital mexicana y su particular configuración como grupo inmigratorio. Los españoles en México, durante este periodo, eran un grupo caracterizado por una escasa afluencia numérica, que nunca representó más del 0,2\% dentro del conjunto de la población. Pese a ello, eran el grupo extranjero más numeroso, seguido de guatemaltecos y estadounidenses, cuya presencia dentro de la inmigración extranjera en México era aún menor. ${ }^{1}$ Así, en 1877 había 6.400 peninsulares en toda la República, que llegaron a ser casi treinta mil en vísperas de la Revolución Mexicana (1910), lo que representa un aumento promedio de setecientos individuos al año (Lida, 1994, p.30). De estos, 40\% residían en la Ciudad de México, lo que resultaba en un número de 6.300 individuos para 1900 y casi el doble para la década siguiente (Gil Lázaro, 2015, p.37). Asimismo, se trata de una inmigración singularizada por su inserción en sectores económicos que proporcionaban grandes capitales y beneficios, como la industria, el comercio, la banca o las empresas agrícolas, de las que en muchas ocasiones eran propietarios. Sin embargo, el 
grueso de la población se dedicaba al comercio, en calidad de dependientes, sector en el que era común experimentar un ascenso socioeconómico a lo largo de los años de trabajo (Pérez Herrero, 1981; Jarquín, 1981). Todo lo anterior ha merecido que la inmigración española en México haya sido calificada como "privilegiada" (Lida, 1994). Muchos de los individuos pertenecientes al primer grupo se asociaban en el Casino Español, lugar en el que fortalecían sus lazos económicos mediante el contacto con otros grandes hombres de negocios y donde llevaban a cabo una sociabilidad restringida con otros miembros de su mismo nivel socioeconómico, lo que aumentaba su reconocimiento como miembros de la élite (Herrera Lasso, 1998; Gutiérrez Hernández, 2004). Por último, a los grandes comerciantes y dependientes de comercio se sumaban, en menor número, aquellos españoles dedicados a otras actividades laborales, así como los que se ubicaban en un escalafón social más bajo, quienes se encontraban desempleados, contaban con una escasez de recursos o estaban en situación de indigencia.

La SBE estaba administrada por el sector mejor posicionado de la colectividad, con el objetivo de atender a los menos afortunados, por lo que fue la respuesta "dada por los primeros" ante los desequilíbrios generados por el propio fenómeno migratorio (Llordén Miñambres, 1995, p.152). Por su parte, la Quinta de Salud fue una propuesta derivada de los dependientes de comercio de origen español, quienes a fines del siglo XIX cuestionaron el funcionamiento asociativo de la colectividad, basado en el control de las instituciones de la colonia por los españoles más acaudalados los cuales se vinculaban con el gobierno mexicano por medio de relaciones políticas y personales. Aunque la Quinta de Salud tuvo una duración muy corta y un impacto bastante limitado en la práctica, resulta interesante prestar atención al proyecto, pues es representativa no solo de los retos que enfrento La Beneficencia, sino también de sus carencias.

Cada una de las instituciones anteriores tenía un periódico (o varios) que, aunque de manera informal, actuaba de facto como su vocero. Así, la SBE contó, entre 1873 y 1914, con las siguientes publicaciones: La Iberia (1867-1876), La Colonia Española (1873-1879), ${ }^{2}$ El Centinela Español (1879-1883), La Voz de España (1879-1888), El Pabellón Español (18831890) y El Correo Español (1890-1914). Por su parte, La Nación Española (1900-1901) actuó como portavoz de la Quinta de Salud. La asociación de estas instituciones con órganos de prensa resultaba fundamental, ya que estos periódicos publicaban información acerca de la celebración de reuniones y juntas entre los socios. Sobre La Nación Española, cabe destacar que fue una publicación que, en el contexto posterior a la pérdida de Cuba para España (1898), impulsó nuevas propuestas de organización asociativa para la comunidad española, en clara oposición al grupo reunido en torno a El Correo Español, vocero del Casino Español y la élite de la colectividad (Granados García, 2000, p.417). En esta coyuntura surgió la Quinta de Salud, de alcance muy restringido pero a la que es importante prestar atención como muestra de las actividades que se promovieron. La única información que hasta el momento se ha encontrado sobre la Quinta de Salud se encuentra en las páginas de La Nación Española.

La "caridad", la "beneficencia", la "filantropia" y la "asistencia" son términos con los que se refirió la labor realizada por la SBE, algunos de los cuales fueron posteriormente cuestionados por los individuos que impulsaron la Quinta de Salud. Además, fueron 
característicos de los debates ideológicos y las prácticas sociales de la época, por lo que una breve atención a su significado resulta pertinente. La "caridad" se relaciona con la idea de limosna a los pobres, que se llevaba a efecto de manera indiscriminada por parte de particulares y que en la mentalidad cristiana permitía salvar el alma del donante. La "beneficencia" se inspira en la caridad cristiana, pero implica una modernización respecto a la manera en que se considera la atención a los más desfavorecidos - pobres y enfermos -, pues supone la concentración de la ayuda en una institución, como parte de un plan para racionalizar las labores de asistencia. Así, la "beneficencia" formaba parte de un proyecto para favorecer al conjunto de la sociedad. En relación con el proyecto institucional, los individuos que se encontraban al frente se caracterizaban por su labor "filantrópica", pues en teoría buscaban resolver la cuestión de la pobreza y la enfermedad sin obtener réditos a cambio. Por último, la labor "asistencial" era la que se realizaba dentro de estas asociaciones de "beneficencia", las cuales incluían una amplia gama de actividades que variaban según la institución (Arrom, 2011, p.80).

\section{La salud durante el Porfiriato}

La SBE fue fundada en 1842 por el cónsul español Francisco Preto y Neto, con la intención de socorrer a los españoles pobres y enfermos, enterrar los cadáveres de personas de escasos recursos y ayudar a los inmigrantes españoles a encontrar un trabajo en la capital del país (Matute, 1966, p.13). No obstante, como indica Gil Lázaro, no fue hasta las décadas de 1870 y 1880 que puede considerarse una agrupación económica y socialmente poderosa, momento en que consolidó sus estatutos, creó el primer asilo-hospital para la colectividad española y se dotó de una fuente de financiación privilegiada: la Junta Española de Covadonga, cuyo fin principal era conseguir recursos para sufragar los gastos de la SBE (Gil Lázaro, 2015, p.135). Además, en 1901 la SBE obtuvo el reconocimiento de personalidad jurídica, lo que situó a la asociación y sus dirigentes bajo la mirada del Estado y permitió la consolidación de vínculos políticos e institucionales, que ya existían en el ámbito económico y financiero, entre la cúpula dirigente de la colonia española y el gobierno de Porfirio Díaz. ${ }^{3}$ Así, el Porfiriato fue la época de consolidación de la labor asistencial de los españoles en México.

Lo anterior no debe obviar la preeminencia que durante este periodo adquirió el discurso sobre la salud pública en México, como consecuencia de la gradual centralización, profesionalización y expansión de los servicios médicos. Esto se debía al objetivo de Díaz de implementar políticas que llevaran al país por la senda de la civilización y el progreso, con el objetivo de insertar a México en el concierto de las naciones "modernas" (Carrillo, 2002). La introducción de medidas sanitarias, en particular en el área urbana, resultaba fundamental para la imagen de una ciudad moderna, por lo que higienistas, médicos e instituciones de salud adquirieron en esta época un impulso sin precedentes por parte del Estado (Soto Laveaga, Agostoni, 2011, p.563; Agostoni, 2003). Además, en el proceso de pacificación del país que caracterizó al régimen de Díaz, la labor de la beneficencia era un mecanismo útil para conseguir el equilibrio social, pues apelaba a la utilización de recursos para aliviar la miseria y la enfermedad (Padilla Arroyo, 2004, p.151). Así, la expansión de la 
SBE corrió de manera paralela al fortalecimiento de la Beneficencia Pública en México, que durante este periodo experimentó un progresivo proceso de federalización (Lorenzo Río, 2017). Por último, es importante asociar la pacificación de México con el deseo de abrir el país a las inversiones y fomentar la expansión capitalista, donde participaron de manera muy activa los individuos mejor posicionados de la colectividad española. Finalmente, este periodo de bonanza económica dio lugar a un aumento de la inmigración española. Así, modernización, pacificación, expansión de los servicios médicos, desarrollo capitalista y aumento de la emigración repercutieron de manera favorable en el crecimiento de la SBE.

\section{La Sociedad de Beneficencia Española: la Casa de Salud y Asilo}

La SBE responde al modelo asistencial inspirado en la caridad cristiana pero promovido por particulares sin relación institucional directa con la Iglesia católica. No obstante, las enfermeras que atendieron la SBE fueron, en un primer momento, las Hermanas de la Caridad - hasta su expulsión de México en 1873 - y luego las religiosas josefinas, que renunciaron en 1901 como consecuencia de una serie de quejas por parte de personas que no estaban conformes con sus servicios. Esto dio lugar a la propuesta para traer de España a las Hermanitas de los Pobres, para que a partir de entonces se ocupasen de la Casa de Salud y Asilo (Vieyra, 2010, p.475; Laguarta, 1955, p.292). Lo anterior refleja que el asistencialismo liberal, del cual es representativa la SBE, estuvo concebido en base a criterios tradicionales de atención a pobres y enfermos. En este sentido, Esteban de Vega sostiene que los poderes públicos y las iniciativas individuales se limitaron a controlar la desaparición del aparato asistencial del antiguo régimen y sustituirlo por otras iniciativas benéficas, por lo que no es sorprendente la presencia de las religiosas como enfermeras (Esteban de Vega, 1992, p.124-125). Este modelo de beneficencia privada, destinado a la atención de pobres y enfermos, convivió con la beneficencia pública, a partir de la Ley de Secularización de Hospitales y Establecimientos de Beneficencia (1861), de perfil liberal. En lo sucesivo, los establecimientos de atención a pobres y enfermos patrocinados por la Iglesia católica serían administrados por la Federación (Padilla Arroyo, 2004, p.128-132). ${ }^{4}$ De hecho, la secularización de la asistencia nunca supuso el monopolio de la misma por parte del Estado, pues la carencia tanto de recursos - y, en ocasiones, de voluntad política - para crear una red de protección social a huérfanos, ancianos o enfermos, permitió un amplio margen de acción para la iniciativa privada (Esteban de Vega, 1992, p.132).

En este contexto, los filántropos españoles que dirigían la SBE dotaron a la colectividad de este origen de un espacio propio para la atención médica y hospitalaria: la Casa de Salud y Asilo, que actuaba de manera paralela a las iniciativas estatales. Lo anterior permitía ubicar a la institución y a sus dirigentes en un sistema de relaciones dentro de la sociedad que les aseguraba un lugar de privilegio y reconocimiento social, debido a la creciente importancia de los proyectos en torno a la salud. El ejercicio de la caridad privada, junto con la administración de la asistencia pública, se convirtieron en piezas centrales a la hora de definir la identidad de los círculos afines a Porfirio Díaz. Así, los actos institucionales de caridad privada estaban relacionados con la construcción y consolidación de una identidad cívica, por parte de las clases políticas y sociales leales a Díaz. Esto es lo que ha dado lugar 
al término de "benevolencia conspicua", acuñado por Ann S. Blum (2001, p.31) para hacer referencia a las iniciativas benéficas privadas por parte de individuos que querían consolidar sus relaciones con el gobierno porfiriano. ${ }^{5}$ Desde 1901 la SBE se atuvo a los lineamientos establecidos en la Ley de Beneficencia Privada para el Distrito y Territorios Federales (1899), obteniendo el reconocimiento de personalidad jurídica y abriendo la sociedad a la eventual vigilancia del Estado mexicano (Ley..., 6 nov. 1899, p.2-6). ${ }^{6}$ Además, se reglamentó la posibilidad de recibir donativos y beneficiarse de exenciones fiscales que, en el caso de la SBE, resultaron en la liberación de impuestos para el Panteón Español. ${ }^{7}$

Como indica Gil Lázaro, antes de la adquisición de un local propio, la SBE había rentado diferentes espacios y pagado una cuota por el cuidado de sus enfermos en distintos hospitales de la Ciudad de México (Gil Lázaro, 2015, p.298). A partir de 1860, por medio de un acuerdo con el Ayuntamiento, arrendaba una sala con seis camas en el Hospital de San Pablo - denominado Hospital Juárez desde 1872 -, en la que se alojaban tanto los españoles enfermos como aquellos recién llegados a México sin familia con la que alojarse ni medios para subsistir, de tal manera que la habitación fungía también como "hotel de inmigrantes". El Hospital estaba atendido por varios médicos y por las Hermanas de la Caridad. No obstante, la sala de españoles contaba con médicos pagados por la propia SBE, lo que aunque en principio contravenía el acuerdo establecido con el Ayuntamiento se llevaba a cabo con total normalidad (La Sociedad..., 1870, p.5-6). A partir de 1870 se hizo evidente la necesidad de aumentar el espacio para alojar a los pacientes, así como de establecer una separación entre los enfermos comunes y aquellos febricitantes o con enfermedades contagiosas; y de estos con los asilados. ${ }^{8}$ Por ello, la SBE solicitó la mudanza a un local contiguo a la sala que en ese momento ocupaban, dentro del mismo hospital, con el objetivo de satisfacer las comodidades y condiciones higiénicas y de salud antes mencionadas. Además, con esta mejora, la asociación española planeaba aumentar el número de socios de la Beneficencia, lo que previsiblemente traería un incremento en el número de pacientes, que en los últimos años se había reducido debido a la "falta de un establecimiento que responda convenientemente las exigencias de la misma" (La Sociedad..., 1870, p.2).

El traslado de la sala de los españoles dentro del Hospital de San Pablo se verificó a lo largo del año siguiente (1871) y las obras necesarias para cumplir con los requisitos previos fueron sufragadas por el propio Ayuntamiento. ${ }^{9}$ Las condiciones establecidas por la SBE para la nueva sala se plasmaron en un plano, encargado al arquitecto don Lorenzo Hidalgo por la propia SBE (La Sociedad..., 1870, p.3), en el cual se establecía por primera vez la separación entre los enfermos contagiosos - quienes contaban con una habitación propia - y los enfermos comunes. No obstante, ambos tipos de pacientes compartían un mismo baño, mientras que el acceso a la sala de los aquejados con enfermedades infecciosas podía realizarse tan solo mediante la sala general de enfermos. Estos datos muestran tanto la incorporación de los nuevos saberes médicos del periodo como sus limitaciones, reflejadas en la manera en que se implementaron estos nuevos conocimientos. De manera adicional, se construyó una zona de tránsito para aislar completamente a los enfermos de los asilados, quienes contaban con un comedor propio. Por último, cabe destacar que aunque la SBE solicitó la creación de un acceso independiente del resto del hospital, exclusivo 
para la atención de los españoles, este no llegaría a concretarse porque el ayuntamiento no lo aprobó (La Sociedad..., 1870, p.24). A excepción de este último aspecto, las obras se ejecutaron tal y como había dispuesto Lorenzo Hidalgo, siguiendo las instrucciones de la SBE. No obstante, en 1874 la atención a los españoles enfermos se trasladó al Hospital de San Cosme, aludiendo a los deseos de "mejorar las condiciones de temperatura" (Mayora Martín..., 1874a, 1874b), lugar en el que la SBE se mantendría también a lo largo del año siguiente. Así, entre 1860 y 1875, la SBE se encontraba inserta dentro del sistema público de hospitales, en lo que se refiere a la infraestructura; pero administrada de manera privada, como hemos visto.

Como indica Gil Lázaro (2015, p.160), en 1876 la SBE compró un edificio en el n.17 de la calle Niño Perdido - cuartel VI, actual Eje Central Lázaro Cárdenas, entre avenida Dr. Río de la Loza y Dr. Lavista -, que hasta 1932, cuando se construyó el actual Sanatorio Español, sería la Casa de Salud y Asilo de los españoles en la Ciudad de México, el primer hospital propio con que contó la colectividad de este origen. ${ }^{10}$ La ubicación del asilo-hospital fue calculada en base a los criterios urbanísticos de la época "debido a que suposición en el extremo sur de la ciudad le libra de la fuerza y peligro de los vientos reinantes en la capital, y merced también a varios hornos de fábricas que hay por aquel rumbo, y que coadyuvan a purificar la atmósfera". Además, la Casa de Salud contaba con un pozo de agua potable, "un hermoso estanque" y "tomando en cuenta los modernos adelantos de la higiene, además de los baños habituales que se construyen, se establecen regaderas y duchas en que se puede disponer de agua caliente" (Carreño, 1942, p.175, 192). La comprensión de estas características como las ideales para la salud e higiene pública se relaciona con estudios contemporáneos que coadyuvaron a la circulación de nuevos saberes médicos. Entre estos destaca el del doctor Domingo Orvañanos Orvañanos (1889), quien en su Ensayo de geografía médica y climatológica establecía la importancia de conocer las características de los vientos para saber sus efectos en el cuerpo humano o el nivel de calidad del agua para el mejoramiento de la salud, entre otras cuestiones.

La Casa de Salud del Niño Perdido fue aumentando sus instalaciones conforme las necesidades lo iban requiriendo, es decir, a medida que la demanda de atención de enfermos se incrementaba cada vez más (en relación directa con el aumento de españoles que llegaban a la ciudad), y de acuerdo a un plan no racional. Así, un año después de la adquisición del primer local se compró un corral adyacente al sanatorio; en 1890 se compró una casa en la Calzada del Campo Florido, que lindaba por el este con los inmuebles anteriores; en 1898 y 1899 se compraron otras dos casas que limitaban por el sur con las edificaciones anteriores; ${ }^{11}$ en 1906 se compró una fracción más de la misma Calzada. Finalmente, todo el complejo del Hospital Español sería completado en 1918. El primer local se compró por un precio de $\$ 3.500$, a lo que se agregaron las sumas de $\$ 700, \$ 9.000, \$ 3.000, \$ 5.000$, $\$ 10.000$ y $\$ 18.000$, correspondiente a las respectivas ampliaciones, arrojando un monto total de $\$ 49.200$. Lo anterior permite dar una idea de la desigual evolución del entonces Hospital Español, que se encontraba en función de la liberación de espacios urbanísticos adyacentes al predio inicial y merced a las facilidades otorgadas por el Ayuntamiento. En total, las propiedades anteriores terminaron por ocupar una superficie total de $6.925 \mathrm{~m}^{2}$, de los cuales $1.945 \mathrm{~m}^{2}$ correspondían a espacios abiertos y lo restante era construido. ${ }^{12}$ 
Respecto a cuestiones de tratamientos y enfermedades, la intención inicial fue que el sistema de curación en la Casa de Salud fuera el homeópata, y así fue implementado en 1876. No obstante, el año siguiente se comentó en la junta directiva que el sistema homeopático "no había sido admitido aún por ninguno de los establecimientos oficiales del mundo", por lo que se regresó de nuevo al sistema alopático (Laguarta, 1955, p.256). Otra característica del nuevo asilo-hospital fue que al momento de su fundación prohibió la admisión a los enfermos de sífilis - que no obstante serían incorporados unos años más tarde -, mientras que la asistencia a las enfermedades crónicas se realizaría solo por un periodo máximo de dos meses, a excepción de las personas suscritas a la SBE y que se encontraran al corriente de los pagos a la asociación (Carreño, 1942, p.155-158, 175). Lo anterior probablemente se debía a lo costoso que resultaba para la sociedad el tratamiento de estas enfermedades, las cuales implicaban un largo periodo de convalecencia. Como indica Gil Lázaro, a fines del siglo XIX, los padecimientos que se trataban en la Casa de Salud eran fundamentalmente los infecciosos (viruela, sarampión, tifo y erisipela) y las enfermedades venéreas (entre las que destacaba la sífilis), seguidos de reumatismo, pulmonía, tuberculosis, enfermedades del aparato digestivo, respiratorias etc. A medida que avanzó el nuevo siglo, se fueron incorporando en número notable las operaciones quirúrgicas, la medicina interna y las enfermedades de la piel; así como la capacidad de la Casa de Salud para atender estos padecimientos (Gil Lázaro, 2011a, 2011b). A partir de 1901 apareció una serie de anuncios en El Correo Español publicitando el antisifilítico "Oriental Africano" como una vía para atraer a los enfermos de sífilis a la Casa de Salud de la SBE, lo cual es indicio del gran número de afectados por esta enfermedad y los réditos que ello podía proporcionar a la sociedad en términos de aumento de socios (El gran medicamento..., 5 oct. 1901). Todo lo anterior refleja la introducción de tratamientos relacionados con los avances bacteriológicos de la época, que durante las dos últimas décadas del siglo XIX comenzaron a consolidarse a nivel internacional. ${ }^{13}$ Por último, resulta interesante observar cómo a comienzos del nuevo siglo ya se llamaba la atención acerca de que "entre las medidas que más urgentemente reclaman nuestro esfuerzo, figuran ... la mejora del asilo permanente para los inválidos ... por los accidentes de trabajo" (Circular, 16 mar. 1901). Lo anterior puede relacionarse con el perentorio asunto de la "cuestión social", pues en el contexto de la rápida urbanización e industrialización de la ciudad, así como la falta de garantías laborales y la persistencia de las desigualdades sociales, se temía la emergencia de una clase obrera militante (Blum, 2001, p.9).

Como indica Gil Lázaro, la Casa de Salud y Asilo comprendía un espacio para alojar a los enfermos, otro para las consultas médicas y un albergue para dar cobijo a los ancianos e indigentes. No obstante, la atención a estos últimos fue minoritaria y las labores de la Casa de Salud y Asilo se centraron en la atención a los enfermos. En 1899 el hospital contaba con cincuenta camas, que en 1909 se ampliaron a ochenta. En términos de afiliación podemos observar la pujanza de la SBE, que pasó de tener 269 socios en 1843, a cuatrocientos en 1862, 1.044 afiliados en 1887, 3.191 miembros en 1905 y 4.325 cuando acabó el Porfiriato, en 1910. En la misma época la otra asociación de referencia de la colectividad, el Casino Español, oscilaba entre los trescientos y setecientos socios (Gil Lázaro, 2015, p.127-130). Aunque la SBE se regía por un sistema de cuotas para sus miembros, el perfil caritativo de 
la asociación estableció en 1892 que la Casa de Salud acogería a los españoles enfermos, sin recursos, sin lugar donde alojarse o que no contasen con medios de subsistencia. No obstante, a lo largo de este periodo, en ningún caso se atendería a mujeres ni a niños menores de 10 años. Además, la atención a los socios de la SBE era preferente por encima de los que no lo eran (Gil Lázaro, 2015, p.163-173). Según Lilia Vieyra (2010, p.486), a los enfermos pobres se les atendía en horarios diferentes y en salas separadas. Lo anterior muestra el interes por parte de los dirigentes de la asociación en crear una asociación de perfil paternalista, con relaciones de poder y lineamientos jerárquicos en base a la nacionalidad (atención únicamente a españoles, al contrario del funcionamiento de otras asociaciones, como la francesa), ${ }_{1}^{14}$ la clase (atención privilegiada a los socios y segregación de los enfermos pobres, al tiempo que se planteaba la obligación de que los más favorecidos económicamente auxiliasen a los más necesitados, apelando a la caridad), el género (los hombres como merecedores exclusivos de la atención médica) y la edad (ausencia total de atención a la infancia).

Como muestra Gil Lázaro (2015, p.176-185), la financiación de la SBE procedía de fuentes muy diversas: las suscripciones de los socios, la Casa de Salud, el Panteón, donativos, cesiones, así como los rendimientos que generase la propia institución; aunque la mayor parte provenía de los tres primeros rubros, lo cual constituía entre el 70-90\% de la financiación que, por tanto, tenía un origen privado. Además de lo anterior, durante el Porfiriato cabe destacar la celebración de corridas de toros con el objeto de financiar las actividades de la Casa de Salud y Asilo. Con este fin, en diversas ocasiones se solicitó al Ayuntamiento que eximiera a la SBE del pago del impuesto del 15\% que aplicaba para todos los eventos relacionados con diversiones públicas, entre los que se encontraban los toros. No obstante, la respuesta del Ayuntamiento siempre fue que no resultaba posible satisfacer la petición, ya que este impuesto estaba destinado a financiar las obras del desagüe del valle de México y emprender la labor de saneamiento de la ciudad (Benito..., 1887). A partir de 1895, la SBE ideó un mecanismo administrativo donde jugaba un importante papel el elemento discursivo. Así, trás exponer lo costoso que resultaba para la sociedad el pago del impuesto mencionado, pero manifestando que comprendían la necesidad de cumplir con este, los presidentes y secretarios de la SBE solicitaban al Ayuntamiento que a cambio fijase una contribución para la corrida de toros "equivalente al término medio del producto que haya obtenido el Ayuntamiento en las últimas dos corridas de toros", para "aliviar los dolores de sus semejantes" (Quintín Gutiérrez..., 1895). En la práctica, la contribución del Ayuntamiento a la SBE suponía el equivalente a la reducción del 34\% del total del impuesto municipal. ${ }^{15}$ Lo anterior muestra otro de los mecanismos de financiación de la SBE, que por este medio se allegaba recursos públicos, que eran destinados a fines privados. Asimismo, la SBE solicitó al Ayuntamiento en diversas ocasiones que se le eximiera del pago de otros impuestos - derivados de la necesidad de hacer reformas, ocupar la vía pública con material de construcción o la exención de impuestos municipales de aguas, pavimentos y atarjeas-, alegando el "objeto a que se dedica dicha finca, objeto que siempre ha encontrado el más poderoso auxilio en las autoridades" (El Presidente..., 1891; Miguel Díaz..., 1899; Peláez..., 1890). ${ }^{16}$ Gil Lázaro, muestra que los gastos de perfil más caritativo fueron menores en el cómputo total de la SBE - no se destinaba más de un $10 \%$ de los gastos a este rubro ${ }^{17}-$, 
pero tenían un enorme peso simbólico. Esto se encontraba relacionado con el proyecto de caridad cristiana sobre el que descansaba la sociedad, el cual se manifestaba sobre todo a través de la vía discursiva y constituía el sostén ideológico para el mantenimiento del status social de los directivos de la asociación. Los componentes discursivos centrales oscilaban entre la apelación a la virtud cristiana y el patriotismo español, por lo que el interés en proteger a los españoles por parte de los más pudientes, lo cual se planteaba en términos de solidaridad y obligación, se expresaría mediante la atención a los enfermos y el apoyo a quienes no tuvieran recursos (Gil Lázaro, 2011b, p.101, 2015, p.185-191). Todo lo anterior muestra que la SBE era un proyecto comunitario para fomentar la unidad del grupo de españoles, sobre una base jerárquica. ${ }^{18}$

\section{La Nación Española: el Centro de Dependientes y la Quinta de Salud}

Para que este artículo no acabe por reflejar una visión triunfalista y laudatoria de la SBE, resulta necesario indagar en las insatisfacciones que generó y las aspiraciones de los inmigrantes que finalmente no logró cumplir, fundamentalmente la de aquellos que trabajaban en actividades comerciales. ${ }^{19}$ La experiencia de la guerra de Cuba (1895-1898) dio lugar a que en los años posteriores al final del conflicto se produjese un gran enfrentamiento dentro de la colonia y un fuerte cuestionamiento de las bases identitarias de los españoles y los fundamentos sobre los que se asentaba la experiencia asociativa. ${ }^{20}$ En este contexto se fundó el periódico La Nación Española (1900-1901). Esta publicación estaba vinculada a una iniciativa para renovar la organización de la colonia española en la Ciudad de México en torno a un proyecto que situaba como protagonistas a los dependientes de comercio; ${ }^{21}$ en oposición al sector mejor posicionado desde el punto de vista socioeconómico - propietarios, capitalistas, industriales y banqueros, fundamentalmente -, que ostentaban la dirigencia del Casino Español, la Cámara Española de Comercio ${ }^{22}$ y la SBE.

La Nación Española representa una ventana a las insatisfacciones de los españoles en México, sobre todo en lo que respecta a su relación con las instituciones de la colonia que se arrogaban la representación de este colectivo de inmigrantes. En lo que se refiere a la SBE, esta publicación buscó divulgación y legitimidad mediante la publicación de las experiencias sufridas por los españoles atendidos en la Casa de Salud y Asilo. Lo anterior reviste una particular importancia, pues se trata de la única fuente documental existente acerca de la visión que algunos pacientes tenían del hospital de la colonia, sobre todo aquellos que - por diversas razones - se encontraban más descontentos con la atención brindada. Evidentemente, por los intereses del periódico, no se recogieron las opiniones favorables a la institución benéfica; las cuales, por otro lado, eran las que solían circular en los periódicos hegemónicos de la colonia, como en ese entonces era El Correo Español. Así, en su primer número, el periódico informaba de la inhospitalidad que sufrían los españoles en México, pero "no de México, que es muy hospitalaria, sino de muchos españoles que no acogen con hospitalidad a muchos españoles" (Inhospitalidad, 1 sep. 1900). Desde entonces las quejas hacia la SBE y su Casa de Salud proliferaron en el nuevo periódico. A continuación se copian las más representativas: 
el día último de octubre fue atacado por la pulmonía un socio de la Beneficencia ... acudió a la Beneficencia, en demanda de asilo, pero era día de fiesta ... volvió al siguiente día, y como era fiesta también, las oficinas no estaban abiertas. El pobre enfermo volvió al tercer dia ... y a las pocas horas de ingresar al 'benéfico' establecimiento, entregó su alma á Dios. ... ¿Qué importa que se muera un enfermo por falta de oportuno auxilio, si en cambio se emplean dos días en 'cumplir' con la Iglesia? (Beneficencia..., 20 nov. 1900; énfasis adicional).

La Beneficencia Española de México, no sabemos si será española, pero nos consta que no es Beneficencia ... Si en nuestras manos estuviera, el palacio de la calle del Niño Perdido, llenaría su misión debidamente (Chismes..., 30 nov. 1900).

El día 26 de enero próximo pasado, ingresó a aquella casa nuestro compatriota D. Jesús Fernández, y el día 26 se le hizo una delicada operación. Las pocas ó ningunas atenciones que con él se tuvieron después, hizo que el paciente reclamara. ... El día que lo hizo ... fue arrojado á la calle á petición de la superiora y de los practicantes (¡Oh, la Beneficencia!, 2 feb. 1901).

para formar las Juntas Directivas siempre se echa mano, no de los más capaces, antes bien, de los más ricos, como si la plata aumentara las circunvoluciones cerebrales, ... lo que da por resultado que ... las quejas se pierdan en el vacío (La Beneficencia..., 16 mayo 1901).

El contenido de las quejas se orienta hacia los siguientes aspectos: escasa calidad de la atención médica, en oposición a un fuerte discurso caritativo; ineficacia de la atención a los pobres y enfermos más necesitados, frente a la ostentación económica de sus dirigentes y pésima administración de la institución, en detrimento de los pacientes. En suma, el descontento recogido en estas líneas trataba de cuestionar la supuesta "caridad" y "filantropía" practicadas por la pretendida "Beneficencia" Española en sus labores "asistenciales".

Como afirma Gil Lázaro (2015, p.185), lo anterior hacía referencia a las bases fuertemente jerárquicas sobre las que se había organizado el sistema asistencial de la SBE que, al estar en manos de los miembros de la cúspide del poder económico, impusieron unas reglas de funcionamiento que situaban a los enfermos en una posición de absoluta subordinación, basada en la idea de que sobre ellos se ejercía una acción generosa y caritativa. Además, La Nación Española opinaba que "la llamada Beneficencia ... no es sino Sociedad de socorros mutuos" (¿Con qué derecho?, 28 dic. 1900), lo que en realidad aludía al hecho de que la principal fuente de financiación provenía de las cuotas de los miembros y, en consecuencia, eran ellos los privilegiados en la asistencia. De este modo, el entramado caritativo se encontraba en conjunción con una organización más bien mutual (Gil Lázaro, 2011b, p.101).

La exposición pública del descontento anterior propició que el equipo directivo de La Nación Española impulsara la fundación del Centro de Dependientes del Comercio, una nueva asociación formada por jóvenes españoles asalariados en diferentes ramos del comercio. La mayoría trabajaba en tiendas de abarrotes, pero era notable también su presencia en las cantinas, panaderías, tiendas de ropa y casas de empeño, que en muchas ocasiones eran propiedad de otros españoles. El objetivo del centro era proporcionar a los dependientes un lugar de sociabilidad propio y destinar un espacio para la formación 
en estudios del ámbito mercantil (Un paso..., 15 sep. 1900). Además, entre los objetivos prioritarios estaba la creación de una Quinta de Salud. Con estos fines se aprobaron los estatutos de la nueva asociación y, en lo que respecta a la salud, se organizó una comisión de beneficencia: "el único requisito será la exhibición de los recibos expedidos por la Junta, al corriente. Se nombrará una Comisión Vigiladora de Enfermos, que se encargará de cuidar que todo socio enfermo sea medicinado y auxiliado con escrupulosidad" (Centro..., 22 sep. 1900). Además, los estatutos incluían los siguientes artículos:

Art. 52. La Comisión de Beneficencia tiene por objeto proporcionar los medios de curación de los asociados, los cuales no podrán hacer uso de este derecho sino después de dos meses de haberse inscrito.

Art. 54 ... II. Inspeccionar y resolver cuanto se relacione con la asistencia sanitaria ... IV. Visitar a los enfermos y cuidar se les atienda con el esmero que marca el Reglamento (Estatutos..., 17 dic. 1900, p.30).

Aunque la Quinta de Salud del Centro de Dependientes no comenzó a funcionar hasta febrero de 1901, se coordinaron esfuerzos desde noviembre de 1900 para que los socios pudieran ser atendidos. El doctor Juan Antiga y Escobar, cirujano y médico homeópata, ofrecía atención gratuita en su consulta a todo aquel que demostrase la pertenencia al Centro de Dependientes (Centro..., 7 nov. 1900). A partir de diciembre, el Centro - ubicado en la calle de Santa Clara, cuartel III (actual calle Tacuba, entre Bolívar e Isabel la Católica) -, contó con un consultorio médico donde cuatro doctores atendían de manera gratuita a los socios - un número de más de 1.600 asociados (Un salvaje..., 22 feb. 1901) -, en consulta diaria de 3 a 7 de la tarde (Centro..., 5 dic. 1900; Memoria..., 7 nov. 1900). En febrero de 1901 se inauguró al fin la Quinta de Salud, un local destinado exclusivamente a la atención sanitaria, y se convocaron plazas de practicantes y enfermeros (Centro..., 10 ene. 1901). Su director, el doctor Ricardo Marín - cirujano y especialista en ginecología, pediatría y cardiologia -, era redactor jefe del Boletín de Higiene, órgano oficial del Consejo Superior de Salubridad (Gacetilla, 28 feb. 1901).

La Quinta de Salud revierte interés por constituir la única experiencia conocida hasta el momento de organización mutual de los españoles en la Ciudad de México. ${ }^{23}$ Se trata, además, de una sociedad donde pese a la importancia del elemento de identidad nacional, prevalecía la identidad de oficio: "De cerebros españoles surgió la idea y español será el mayor contingente que aporte a la obra, pero es necesario el concurso de todos, y muy especialmente el de muchos empleados mexicanos, hoy dedicados al comercio, y confundidos con nuestros compatriotas" (Centro..., 12 sep. 1900).

No obstante, la Quinta de Salud nunca llegó a ser un proyecto de salud consolidado. A partir de mayo de ese mismo año, diversos artículos periodísticos dan cuenta de los pleitos que suscitó la fundación del Centro de Dependientes y la Quinta de Salud, entre los impulsores de estas iniciativas y los individuos acaudalados de la colonia. Esto se debía al miedo de que el nuevo proyecto provocase una baja notable en el número de afiliados a la SBE, pues los dependientes de comercio constituían, como se ha comentado, la mayor parte de los españoles residentes en la capital mexicana. Lo anterior desembocó en la cooptación del Centro de Dependientes y la Quinta de Salud por el elemento pudiente de la colonia, 
por medio de maniobras de infiltración dentro de la directiva de la sociedad. ${ }^{24}$ Poco antes del cierre de La Nación Española, sus redactores se lamentaban de que

en el mes de febrero se inauguró oficialmente la Quinta de Salud con muy modesto lunch. Y el domingo pasado nos viene la Directiva con nueva y pomposa inauguración oficial ... y andan ahora como dos novios el Centro y El Correo Español ... La mamarrachada de enumerar las salas de enfermos con los nombres de unas cuantas virtuosas señoritas, no compensa (El diablo..., 24 mayo 1901).

A partir de este momento fueron notables las mejoras materiales advertidas en la Quinta de Salud que pronto tuvo un nuevo y lujoso recinto para alojar a los pacientes ubicado en la antigua residencia del General Juan B. Caamaño. El nuevo hospital contaba con treinta camas distribuidas en seis habitaciones, de las cuales una de ellas estaba destinada al tratamiento de enfermedades contagiosas. Asimismo existía una sala de operaciones. El doctor Ricardo Marín seguía siendo el director, mientras que el gerente era Arturo Marín, su hijo. A ellos se sumaban los médicos doctor Ángel J. Nieto y doctor Juan Antiga y Escobar. La revista El Mundo Ilustrado no dudó en publicar un breve reportaje al respecto, en el que incluyó sendas imágenes de la nueva Quinta de Salud, en la cual pueden observarse el lujo tanto exterior como interior del nuevo espacio destinado a la atención de enfermos (La Quinta..., 26 mayo 1901). No obstante lo anterior, no se ha encontrado más información con posterioridad al mes de junio de 1901. Es muy probable que el espacio desapareciese y fuese destinado a otros fines y que los españoles enfermos volviesen a ser atendidos en exclusiva en la Casa de Salud de la SBE.

Los servicios ofrecidos por la Quinta de Salud habían tenido la intención de alejarse de las políticas caritativas de la SBE y promover un tipo de organización mutual, pues se enfatizaba que la atención a los enfermos sería solo para los socios del Centro de Dependientes que hubiesen pagado su cuota correspondiente. No obstante, hemos observado que en realidad el funcionamiento de la SBE no se encontraba muy alejado de este tipo de actividad. Tampoco cabría suponer que la cuota de la SBE fuese superior a la del Centro de Dependientes, pues este último cobraba $\$ 1,50$ mensual en 1901 (Centro..., 4 nov. 1900), mientras que la Beneficencia cobraba entre $\$ 0,33$ y $\$ 5,00$ en 1863 y en torno a $\$ 2$ en $1924,{ }^{25}$ de tal manera que el monto de la suscripción no varió mucho a lo largo del periodo. Por tanto, más bien cabría pensar que, en el contexto del cuestionamiento acerca de la adecuada organización asociativa para la colonia española, la implementación de un espacio destinado a materia de salud resultaba fundamental.

Para finalizar, cabría preguntarse cuál fue el impacto que la efímera existencia de la Quinta de Salud provocó sobre el funcionamiento asociativo de la SBE. Así, el año 1901 - aquel en que la Quinta fue cooptada por el elemento más pudiente de la colectividad, justo antes de desaparecer cualquier referencia hemerográfica o documental sobre ella coincide con la salida de las religiosas josefinas de la SBE, debido a las quejas expuestas por varias personas que se encontraban disconformes con los servicios de las profesas. Ese mismo año, la SBE se adhirió a los lineamientos de la Ley de Beneficencia Privada. De lo anterior se podría inferir que la existencia de la Quinta de Salud fortaleció una discusión intestina acerca del funcionamiento interno de la SBE que, aunque no era nueva - como se 
há expuesto en páginas anteriores -, permitió la consecución de pequeños logros para los pacientes, como se demostró al forzar la renuncia de las religiosas josefinas debido a quejas de los internos. Por otro lado, la aparición de una sociedad contestataria - la Quinta de Salud - probablemente propició que aquellos individuos que se encontraban al frente de la gestión y administración de la SBE buscaran el respaldo legal de las autoridades porfirianas. Lo anterior no solo abría la sociedad a la eventual vigilancia del Estado mexicano y a las exenciones fiscales, sino que fortalecía el reconocimiento político y social de dicha asociación y de los rectores de la misma.

\section{Consideraciones finales}

La Casa de Salud y Asilo de la SBE, administrada por el sector más pudiente de la colonia española, se fundó en un contexto de crecimiento de las iniciativas de salud, impulsadas durante el Porfiriato. La Casa de Salud incorporaba los avances bacteriológicos de la época en materia de enfermedades contagiosas y venéreas, fundamentalmente, otorgando atención en dichos padecimientos únicamente a los hombres de origen español y mayores de 10 años. Lo anterior permitía a los directivos de la SBE adquirir un fuerte reconocimiento social por parte del grupo nacional al que representaban, así como entablar lazos sociales y políticos con la élite gubernamental, lo cual les beneficiaba en las iniciativas empresariales e industriales que estaban desarrollando de manera paralela en el país. El contexto posterior a 1898 permitió que se cuestionara, desde adentro, la organización asociativa de la colectividad española en la Ciudad de México. Lo anterior se materializó en la fundación del Centro de Dependientes del Comercio, que trató de disputar la legitimidad del sector mejor posicionado de la colectividad y su aparato institucional. Así, la centralidad que adquirió el debate en torno a la utilidad o no de la SBE y, en consecuencia, la necesidad de fundar una Quinta de Salud, muestra la centralidad de las iniciativas de salud para los individuos que trataban de arrogarse la dirección de la colectividad, además de la importancia de los centros de salud a la hora de construir una institución fuerte y poderosa, en el contexto del Porfiriato.

\section{NOTAS}

\footnotetext{
${ }^{1}$ A este respecto, véase la tesis doctoral de Delia Salazar Anaya (2007, p.83), en la que analiza la presencia extranjera en México e incluye datos sobre el número de extranjeros en México durante el periodo del Porfiriato.

${ }^{2}$ El caso de La Colonia Española ha sido trabajado de manera detallada por Lilia Vieyra Sánchez (2010, p.465-489), quien ha estudiado el espacio que se dedicó a algunas actividades de la SBE, como las reuniones de la institución, los avisos para exhortar a los miembros a apoyar con donativos, obras caritativas o la promoción de colectas, aunque no hay una atención especial a aspectos de salud.
}

${ }^{3}$ Sobre los vínculos económicos y financieros entre la élite española y el gobierno de Díaz, véase el estudio de Mario Cerutti (1995), acerca de la importancia del capital y las propiedades de españoles en el proceso formativo de la sociedad capitalista en México. Para un estudio pormenorizado acerca del proyecto económico en México durante el Porfiriato, caracterizado por el desarrollo del libre comercio y la expansión de las comunicaciones, gracias a las concesiones gubernamentales otorgadas a empresas privadas o potentados capitalistas, muchos de los cuáles eran españoles, véase Garner (2003, p.163-192).

${ }^{4}$ No obstante, una visión contraria a la aceptación acrítica de esta postura es la expresada por Silvia Marina Arrom (2007, p.446) a partir de su estudio "Las señoras de la caridad", que matiza el alcance de la 
beneficencia pública en la historia de la asistencia social moderna: "los historiadores de la beneficencia se creyeron la propaganda liberal de que a partir de 1861, cuando el gobierno nacionalizó los establecimientos de beneficencia y creó una agencia para administrarlos, el sistema público suplantó a la Iglesia y a los grupos filantrópicos privados".

${ }^{5}$ Para ejemplos similares en otros países, véase Bryce (2015, p.214, 225).

${ }^{6}$ Desde el comienzo del Porfiriato, Díaz había incentivado la caridad privada y buscó proteger estas iniciativas mediante la regulación estatal. Esto significaba que la caridad privada no podía actuar sin la mirada del Estado, lo que fortalecía el poder de este último. Así, el gobierno ajustó el sistema público de hospitales y otras instituciones (orfanatos, asilos etc.) en consonancia con la proliferación de fundaciones de caridad privadas (Blum, 2001, p.12).

${ }^{7}$ La experiencia asociativa en otros lugares donde también se crearon asociaciones de beneficencia por parte de comunidades inmigrantes, como el caso de Buenos Aires, muestra que los subsidios gubernamentales eran similares al caso mexicano o incluso mayores: financiación parcial por parte del Estado a estas entidades o recepción de una pequeña porción de la Lotería Estatal, entre otras cuestiones (Bryce, 2015, p.217).

${ }^{8}$ En 1870 la SBE pagaba un monto de \$0,75 diarios por paciente alojado en el Hospital, cantidad que no aplicaba para los exclusivamente asilados, por quienes no se pagaba nada (La Sociedad..., 1870, p.5-6).

${ }^{9}$ El monto total de la obra, adelantado por la SBE, fue de \$2.463. La reforma incluía la construcción de paredes para separar los diferentes espacios, la creación de nuevos tabiques, así como la construcción de un techo con cuatro armaduras y la instalación de una cubierta de zinc, entre otras cuestiones menores.

${ }^{10}$ Para consultar la ubicación exacta de la SBE en un plano contemporáneo, véase Reducción... (1899-1900).

${ }^{11}$ Esta ampliación fue posible gracias al proyecto que en ese momento llevaba a cabo el Ayuntamiento respecto del alineamiento y ampliación de la Calzada Chica del Campo Florido, para lo cual era necesario derribar la casa n.16 del Niño Perdido. Como la SBE podía aprovechar una parte de esta casa - en torno a una tercera parte de lo que ocupaba el edificio antes de la demolición - sin afectar al alineamiento; la asociación se comprometió al pago de la mitad de la indemnización que el correspondiente derribo costaría al Ayuntamiento, y la consiguiente adquisición del terreno (José..., 1899).

12 Una imagen del exterior de la Casa de Salud del Niño Perdido, así como uno de sus patios interiores, puede verse en Laguarta (1955, p.163). Los números 5-7 de la revista El Arquitecto estuvieron dedicados al concurso para el nuevo Sanatorio Español, que finalmente se establecería en 1932. Se trata de una fuente documental de gran interés, ya que incluye una serie de antecedentes históricos y datos estadísticos de relevancia para el periodo de estudio (Sociedad..., ene.-mar. 1924, p.2).

${ }^{13}$ Entre 1880-1910 se consolidó la bacteriología a nivel internacional. Con anterioridad, el contacto de las personas con el medio ambiente era la explicación predominante acerca del origen de gran parte de las enfermedades. La consolidación de la bacteriología supuso la atribución de causas concretas - bacterias y gérmenes - a las enfermedades.

${ }^{14}$ La Asociación Francesa, Suiza y Belga comprendía entre sus funciones la atención en una Casa de Salud a los enfermos pobres de estas nacionalidades de manera gratuita, y de pago a los de cualquier nacionalidad (Torre, 1887, p.45-46).

${ }^{15}$ En uno de los casos, el impuesto pagado por la SBE al Ayuntamiento fue de $\$ 1.424,92$, mientras que la contribución del Ayuntamiento a la SBE fue de \$500; en otra ocasión el impuesto pagado por la Beneficencia fue de $\$ 1.575,88$, en tanto el Ayuntamiento aportó $\$ 600$ a la sociedad (Quintín Gutiérrez..., 1895; Los señores..., 1896).

${ }^{16}$ Tan sólo en una ocasión fue denegada la solicitud de exención del pago del impuesto sobre materiales empleado en la Casa de Salud de la SBE (José..., 1897).

${ }^{17}$ Entre estos se incluían: pensiones, pasajes y socorros a inmigrantes sin recursos, ayudas en especie, raciones de comida diaria, entrega gratuita de medicinas a domicilio, enterramiento de los fallecidos en suma pobreza y asilo a indigentes y ancianos sin recursos, entre otros.

${ }^{18}$ Estrategias discursivas similares pueden observarse en las colectividades de inmigrantes de diferentes países (Bryce, 2011, p.91-100).

${ }^{19}$ Moisés Llordén Miñambres (1995, p.166) afirma respecto de este tipo de instituciones, aunque no sólo para el caso mexicano sino a nivel continental, que "pronto se pondrán de manifiesto determinadas insatisfacciones ... que no consiguen cubrir parte de las aspiraciones de algunos inmigrantes, especialmente de aquellos que trabajan en actividades comerciales o en la industria artesanal". 
${ }^{20}$ Sobre el enfrentamiento entre los españoles con motivo del final de la guerra de Cuba y la organización de juntas patrióticas, véase Granados (2000).

${ }^{21}$ El comercio era la ocupación a la que se dedicaba un mayor número de españoles en la Ciudad de México, quienes llegaron a controlar el 49\% del comercio de ultramarinos (Pérez Herrero, 1981, p.124-173).

${ }^{22}$ Fundada en 1889, la Cámara Española de Comercio fue creada por el grupo mejor posicionado de la colectividad, bajo la iniciativa y el patrocinio de la Legación Española en México. No obstante, las primeras décadas de su existencia tuvo una actividad bastante restringida en la práctica (Cano Andaluz, 2009).

${ }^{23}$ Como indica Alejandro Fernández (1992, p.331-333), en España el mutualismo descendía de las formas de previsión social del Antiguo Régimen, como las corporaciones de oficios, y constituyó un intento de paliar la miseria y aislamiento urbano de quienes, provenientes de un pasado rural en el que predominaban los vínculos primarios de la familia y el vecindario, se integraban al trabajo de fábrica. Las sociedades de Socorros Mutuos funcionaban por medio del pago de cuotas periódicas de sus miembros, que permitían a estos tener una mayor participación en la gestión de la asociación, sobre todo en comparación con las entidades caritativas, como la SBE, donde eran mucho más fuertes los mecanismos de control y dirección externos a la propia clase.

${ }^{24} \mathrm{El}$ acercamiento entre el Centro de Dependientes y el Casino Español venía sucediendo desde febrero de ese año, cuando la nueva Junta Directiva del primero, presidida por Emilio Cuenca, comunicó a $L a$ Nación Española su decisión de que abandonara el local que compartía con esta sociedad. El Centro siguió bajo la presidencia de Emilio Cuenca a lo largo de 1901 (Centro..., 18 ene. 1901; La Nación..., 5 feb. 1901).

${ }^{25}$ En 1863 la mayoría pagaba entre \$0,50-2,00 (Sociedad..., ene.-mar. 1924, p.1-2).

\section{REFERENCIAS}

AGOSTONI, Claudia. Monuments of progress: modernization and public health in Mexico City, 1876-1910. Boulder: University Press of Colorado; Ciudad de México: Instituto de Investigaciones Históricas/Universidad Nacional Autónoma de México, 2003.

ARROM, Silvia Marina. Para contener al pueblo: el Hospicio de Pobres de la Ciudad de México, 1774-1871. Ciudad de México: Centro de Investigaciones y Estudios Superiores en Antropología Social, 2011.

ARROM, Silvia Marina. Las señoras de la caridad: pioneras olvidadas de asistencia social en México, 1863-1910. Historia Mexicana, v.57, n.2, p.445-490, 2007.

BENEFICENCIA y... otras cosas. La Nación Española, 20 nov. 1900.

BENITO Quintana y sócios piden... Fondo Ayuntamiento y Gobierno del DF, Diversiones, v.2033, leg.900 (Archivo Histórico de la Ciudad de México, Ciudad de México). 1887.

BLUM, Ann S. Conspicuous benevolence: liberalism, pubic welfare, and private charity in Porfirian Mexico City, 1877-1910. The Americas, v.58, n.1, p.7-38, 2001.

BRYCE, Benjamin. Paternal communities: social welfare and immigration in Argentina, 1880-1930. Journal of Social History, v.49, n.1, p.213-236, 2015.

BRYCE, Benjamin. Los caballeros de beneficencia y las damas organizadoras: el
Hospital Alemán y la idea de comunidad en Buenos Aires, 1880-1930, Estudios Migratorios Latinoamericanos, v.25, n.70, p.79-107, 2011.

CANO ANDALUZ, Aurora. Historia de la Cámara Española de Comercio en México. Ciudad de México: Cámara Española de Comercio, 2009.

CARREÑO, Alberto María. Los españoles en el México Independiente: un siglo de beneficencia. Ciudad de México: M.L. Sánchez, 1942.

CARRILLO, Ana María. Economía, política y salud pública en el México porfiriano, 18761910. História, Ciências, Saúde - Manguinhos, v.9, supl., p.67-87, 2002.

CENTRO de dependientes. La Nación Española, 18 ene. 1901.

CENTRO de dependientes: Quinta de Salud. $\mathrm{La}$ Nación Española, 10 ene. 1901.

CENTRO de dependientes. La Nación Española, 5 dic. 1900.

CENTRO de dependientes. La Nación Española, 7 nov. 1900.

CENTRO de dependientes. La Nación Española, 4 nov. 1900.

CENTRO de dependientes. La Nación Española, 22 sep. 1900.

CENTRO de dependientes. La Nación Española, 12 sep. 1900. 
CERUTTI, Mario. Empresarios españoles y sociedad capitalista (1840-1920). Gijón: Archivo de Indianos, 1995.

CHISMES y cuentos. La Nación Española, 30 nov. 1900.

CIRCULAR. El Correo Español, 16 mar. 1901.

¿CON QUÉ DERECHO? La Nación Española, 28 dic. 1900.

EL DIABLO en la Quinta de Salud. La Nación Española, 24 mayo 1901.

EL GRAN MEDICAMENTO del fin de siglo. $E l$ Correo Español, 5 oct. 1901.

EL PRESIDENTE de la Asociación de Beneficencia Española pide se le exima... Ayuntamiento y Gobierno del DF, Hacienda y Contribuciones, v.2037, leg.1184 (Archivo Histórico de la Ciudad de México, Ciudad de México). 1891.

ESTATUTOS del Centro de Dependientes. La Nación Española, 17 dic. 1900.

ESTEBAN DE VEGA, Mariano. La asistencia liberal española: beneficencia pública y previsión particular. Historia Social, v.13, p.123138, 1992.

FERNÁNDEZ, Alejandro. Mutualismo y asociacionismo. In: Vives, Pedro A.; Vega, Pepa; Oyambru, Jesús (coord.). Historia general de la emigración española a Iberoamérica, v.1. Madrid: Historia 16, 1992. p.331-357.

GACETILLA. El Diario del Hogar, 28 feb. 1901.

GARNER, Paul. Porfirio Díaz: del héroe al dictador: una biografía política. Ciudad de México: Planeta, 2003.

GIL LÁZARO, Alicia. Inmigración y retorno: españoles en la Ciudad de México, 1900-1936. Madrid: Instituto de Estudios Latinoamericanos/ Universidad de Alcalá de Henares; Marcial Pons, 2015.

GIL LÁZARO, Alicia. Financiación y gestión de la repatriación de inmigrantes españoles entre 1907 y 1936. Hispania, v.74, n.274, p.465-494, 2014.

GIL LÁZARO, Alicia. Cobertura sanitaria y funcionamiento asistencial de una asociación migratoria: la Sociedad de Beneficencia Española de México, 1910-1936. In: Congreso Internacional de la Asociación Española de Historia Económica, 10., 2011, Sevilha. Actas... Sevilha: Aehe, 2011a. Disponible en: https:/www.aehe.es/wp-content/ uploads/2011/09/Cobertura-sanitaria-yfuncionamiento-.pdf. Acceso en: 6 nov. 2018.

GIL LÁZARO, Alicia. Prácticas mutualistas y discurso caritativo: la Sociedad de Beneficencia
Española de México, 1910-1936. Historia Social, v.70, p.81-105, 2011b.

GIL LÁZARO, Alicia. Crisis, xenofobia y repatriación: los inmigrantes españoles en la Ciudad de México, 1910-1936. Studia Storica, v.28, p.259-292, 2010a.

GIL LÁZARO, Alicia. La repatriación gratuita de inmigrantes españoles durante la Revolución mexicana. Historia Mexicana, v.60, n.2, p.10011057, 2010b.

GIL LÁZARO, Alicia. Billete de repatriación: el retorno subvencionado de españoles entre la Revolución y los años treinta. Tesis (Doctorado en Historia) - El Colegio de México, Ciudad de México, 2008.

GRANADOS GARCÍA, Aimer. Las juntas patrióticas de españoles en México ante el 98: patriotismo, elitismo y proselitismo político. Historia Mexicana, v.49, p.379-429, 2000.

GUTIÉRREZ HERNÁNDEZ, Adriana. Casino Español de México: 140 años de historia. Ciudad de México: Porrúa, 2004.

HERRERA LASSO, Ana Lía. Una élite dentro de la élite: el Casino Español de México entre el Porfiriato y la revolución (1875-1915). Secuencia, v.42, p.177-205, 1998.

INHOSPITALIDAD. La Nación Española, 1 sep. 1900.

JARQUÍN, María Teresa. La población española en la Ciudad de México según el Padrón General de 1882. In: Lida, Clara E. (coord.). Tres aspectos de la presencia española en México durante el Porfiriato: relaciones económicas, comerciantes y población. Ciudad de México: El Colegio de México, 1981. p.178-225.

JOSÉ F. Domec, presidente de la Sociedad de Beneficencia... Ayuntamiento y Gobierno del DF, Calles. Alineamiento, v.448, leg. 346 (Archivo Histórico de la Ciudad de México, Ciudad de México). 1899.

JOSÉ F. Domec, presidente de la Sociedad de Beneficencia... Ayuntamiento y Gobierno del DF, Hacienda y Contribuciones, v.2044, leg. 1719 (Archivo Histórico de la Ciudad de México, Ciudad de México). 1897.

LA BENEFICENCIA Española. La Nación Española, 16 mayo 1901.

LA NACIÓN Española y el Centro de Dependientes. La Nación Española, 5 feb. 1901.

LA SOCIEDAD de Beneficencia Española pide..., Ayuntamiento y Gobierno del DF, Hospitales. San Pablo, v.2311, leg. 100 (Archivo Histórico de la Ciudad de México, Ciudad de México). 1870. 
LA QUINTA de Salud del Centro de Dependientes. El Mundo Ilustrado, 26 mayo 1901.

LAGUARTA, Pablo Lorenzo. Historia de la Beneficencia Española en México: síntesis. Ciudad de México: Editorial España en América, 1955.

LEY de beneficencia privada para el Distrito Federal y Territorios, Diario Oficial de la Federación, 6 nov. 1899.

LIDA, Clara E. Una inmigración privilegiada: comerciantes, empresarios y profesionales españoles en México. Madrid: Alianza América. 1994.

LLORDÉN MIÑAMBRES, Moisés. Una explicación histórica de la acción mutuo-social de las sociedades españolas de emigrantes en América. In: Llordén Miñambres, Moisés (comp.). Acerca de las migraciones centroeuropeas y mediterráneas a Iberoamérica: aspectos sociales y culturales. Oviedo: Universidad de Oviedo, 1995. p.149-171.

LORENZO RÍO, María Dolores. Ley y eficácia: la centralización administrativa de la beneficencia en la Ciudad de México, 1877-1904. Signos Históricos, v.19, n.37, p.64-95. 2017.

LOS SEÑORES Quintín Gutiérrez, José Acha y Sauto y demás socios piden... Ayuntamiento y Gobierno del DF, Hacienda y Contribuciones, v.2042, leg. 1606 (Archivo Histórico de la Ciudad de México, Ciudad de México). 1896.

MATUTE, Ángel. Historia y evolución social de la Sociedad de Beneficencia Española en México. Ciudad de México: [s.n.], 1966.

MAYORA MARTÍN, Secretario de la Sociedad de Beneficencia..., Ayuntamiento y Gobierno del DF, Hospitales. San Pablo, v.2311, leg.147 (Archivo Histórico de la Ciudad de México, Ciudad de México), 1874a.

MAYORA MARTÍN, Secretario de la Sociedad de Beneficencia..., Ayuntamiento y Gobierno del DF, Hospitales. San Pablo, v.2311, leg. 150 (Archivo Histórico de la Ciudad de México, Ciudad de México). 1874b.

MEMORIA... La Nación Española, 7 nov. 1900.

MIGUEL DÍAZ Fernández, Secretario de la Sociedad de Beneficencia..., Ayuntamiento y Gobierno del DF, Hacienda y Contribuciones, v.2047, leg. 1969 (Archivo Histórico de la Ciudad de México, Ciudad de México). 1899.

¡OH, LA BENEFICENCIA!. La Nación Española, 2 feb. 1901.

ORVAÑANOS, Domingo. Ensayo de geografía médica y climatológica. Ciudad de México: Secretaría de Fomento, 1889.
PADILLA ARROYO, Antonio. Del desamparo a la protección: ideas, instituciones y prácticas de la asistencia social en la Ciudad de México, 18611910. Cuicuilco: Revista de Ciencias Antropológicas, v.11, n.32, p.121-155, 2004.

PELÁEZ, Pedro por la Sociedad de Beneficencia... Ayuntamiento y Gobierno del DF, Aguas y Edificios Públicos, v.34, leg. 127 (Archivo Histórico del Distrito Federal, Ciudad de México). 1890.

PÉREZ HERRERO, Pedro. Algunas hipótesis de trabajo sobre la inmigración española a México: los comerciantes. In: Lida, Clara E. (coord.). Tres aspectos de la presencia española en México durante el Porfiriato: relaciones económicas, comerciantes y población. Ciudad de México: El Colegio de México, 1981. p.101-173.

QUINTÍN GUTIÉRREZ y socios piden... Ayuntamiento y Gobierno del DF, Hacienda y Contribuciones, v.2041, leg.1545 (Archivo Histórico de la Ciudad de México, Ciudad de México). 1895.

REDUCCIÓN del Plano oficial de la Ciudad de México, 1899-1900. Compañía Litográfica y Tipográfica SA Antigua Casa Montauriol, ref. 1228-CGE-725-A. (Mapoteca Orozco y Berra, Ciudad de México). 1899-1900.

SALAZAR ANAYA, Delia. Las cuentas de un sueño: la presencia extranjera en México a través de las estadísticas nacionales, 1880-1914. Tesis (Maestría en Historia de México) - Universidad Nacional Autónoma de México, Ciudad de México, 2007.

SOCIEDAD Española de Beneficencia. $E l$ Arquitecto, n.5-7, ene.-mar. 1924.

SOTO LAVEAGA, Gabriela; Claudia, AGOSTONI. Science and public health in the century of Revolution. In: Beezley, William H. (ed.). A companion to Mexican history and culture. Oxford: Blackwell, 2011. p.561-574.

TORRE, Juan de la. La Villa de Guadalupe Hidalgo. Ciudad de México: Imprenta de Ignacio Cumplido, 1887.

UN PASO gigantesco. La Nación Española, 15 sep. 1900.

UN SALVAJE... El Diario del Hogar, 22 feb. 1901.

VIEYRA SÁNCHEZ, Lilia. La Sociedad de Beneficencia Española a través del periódico La Colonia Española (1873-1879). In: Cano Andaluz, Aurora; Cortina, Manuel Suárez; Estrada, Evelia Trejo (ed.). Cultura liberal: México-España (18601930). Santander; Ciudad de México: Publican; Instituto de Investigaciones Históricas/Instituto de Investigaciones Bibliográficas/Universidad Nacional Autónoma de México, 2010. p.465-489.

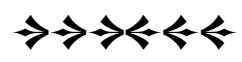

